INTERNATIONAL HIGHER EDUCATION NO. 69 FALL 2012

\title{
Gender and International Research Cooperation
}

\author{
AGNETE VABØ
}

Agnete Vabø is deputy head of research at the Nordic Institute for Studies in Education, Innovation and Science, Oslo, Norway. E-mail: agnete@nifu.no.

The internationalization of higher education and research is becoming increasingly essential, as higher education becomes an industry in which institutions and countries compete for the best brains, exchange students, and collaborate on research. International activity is also increasingly important for the enhancement of individuals' academic careers.

A survey conducted in 2008 within the framework of the international research project, the Changing Academic Profession study, reveals that a much lower share of American academics and United States-based female academics, in particular, reported research collaboration with international colleagues. Given the increasing influence of international collaboration and competition in science and, not at least, efforts of internationalization undertaken in other regions such as the European Research Area, this pattern is striking.

In the United States, only 28 percent of female academics and 37 percent of male academics (of all ranks) report research collaborations with international colleagues. In contrast, in the United Kingdom 69 percent of male and 53 percent of female academics report such collaboration; in Germany, the proportions are 52 percent for men and 43 percent for women academics. 
The highest levels of female participation are found in Australia, Canada, the Netherlands, Finland, Italy, Norway, Portugal, and the United Kingdom. In Latin America-Argentina, Brazil, and Mexico-less than 50 percent of both men and women report taking part in such collaborations.

\section{GENDER AND INTERNATIONALIZATION}

To a certain extent, these gender variations reflect well-established differences that exist between various fields of science, based on modes of international cooperation and publication. Science, technology, engineering, and mathematics disciplines are characterized by more international collaboration and publication than the soft or feminized subjects in the humanities and social sciences.

The Changing Academic Profession's data, nevertheless, suggest that some of these barriers are also related to marital status, spouses' employment, and parental status. It is found that female academics with partners, who are employed full time and with children, are less likely to take part in international research collaboration than male academics (with or without children) and are also less likely to do so than single female academics without children.

The long hours and extensive travel abroad often required by an international career may make it incompatible with the traditional divisions of labor between men and women and may help explain why women academics are more active in internationalization at home. The international career path seems to be a less legitimate option for many women. The Changing Academic Profession's data also reveal that more academic women are single, compared to men. 


\section{IMPORTING AND EXPORTING KNOWLEDGE}

Academics have always been international in the sense of knowledge sharingvia publications, conference attendance, and through sojourns at academic milieus abroad. As is also revealed in the Changing Academic Profession study, academics are often involved in internationalization at home, in teaching foreign students and offering international study programs.

As a large nation with a well-developed academic system, containing many excellent research institutions, across most disciplines and research areas, the United States naturally serves a serious role as an importer of academics and students, rather than as a exporter. Given the range and number of prestigious institutions in North America, international activities are not viewed as being as critical as they often are in European countries, particularly smaller ones. Furthermore, mobility between North American institutions is part of the traditional career dynamic for American faculty. In contrast to many European countries, in the United States it is generally accepted that one should not apply for a first position at the same institution where one has earned a PhD.

\section{BARRIERS TO INTERNATIONAL MOBILITY}

The factors that contribute to the traditional gender roles found in countries also interact with some of the distinctive features of the academic career structures in various countries. Some academic systems are gender segregated, along education-oriented and research-oriented tracks—-for example, in Mexico, which has a low proportion of women at the PhD level. In countries with competitive tenure-track systems, like in the United States, it may be particularly risky for 
women academics to go abroad rather than continue making a name for themselves at home.

The tenure-track system has been argued to hinder international mobility among US academic staff, in general. Academic careers are also characterized by the extensive use of temporary positions. This means that a great deal of importance rests on key stages of an academic career in America, to determine if one can make a name for oneself institutionally-as a researcher, lecturer or supervisor. Consequently, staying abroad is often risky, especially for women, as it could mean losing visibility or dropping out from the national competition for prestige and tenure.

One should not underestimate the extent to which such features limit the realizations of international collaboration and hinder possibilities to profit from such networks and cooperation. More internationalization could not only broaden the basis for collaborating, with excellent academic milieus in other countries and milieus with complementary expertise and data, but could also lead to further funding opportunities. 